\title{
A PEDAGOGIA DA ALTERNÂNCIA NAS CASA FAMILIARES RUARAIS DO PARANÁ:UMA POSSIBILIDADE DE INTEGRAÇ̃̃O ENTRE O ENSINO MÉDIO E A EDUCAÇ̃̃O PROFISSIONAL
}

\author{
Humberto Rodrigues Lima -SEED-PR/UEL ${ }^{1}$ \\ humbertolimapr@hotmail.com
}

\section{INTRODUÇÃO}

A pesquisa foi desenvolvida no estado do Paraná, onde as Casas Familiares Rurais - CFRs são coordenadas pela Associação das Casas Familiares Rurais da Região Sul-ARCAFAR/SUL.

A Região Sul do Brasil é formada pelos estados do Paraná, Santa Catarina e Rio Grande do Sul, tendo 42 Casas no Paraná, 22 em Santa Catarina e 08 no Rio Grande do Sul. No Paraná é onde se concentram maior número de Casas Familiares Rurais.

O objetivo da pesquisa foi de identificar se a Pedagogia da Alternância desenvolvida pelas Casas Familiares Rurais nos cursos técnicos integrados ao ensino médio, tem contribuído efetivamente, para a inserção profissional dos jovens egressos

A partir do conhecimento prévio do currículo escolar desenvolvido nestas instituições, buscamos analisar, se o proposto enquanto qualificação técnica profissional, ofertada aos seus alunos, está surtindo efeito no tocante a inserção destes no mundo do trabalho.

O processo de escolarização com a formação técnica é algo recente ${ }^{2}$ nas Casas do Paraná, portanto os jovens formados ainda se concentram nos cursos de Agropecuária e Agroecologia. Os cursos técnicos são cursos de ensino médio que aqui denominamos de cursos de ensino médio integrado a educação profissional, tem a duração de três anos e os jovens saem com a conclusão da Educação Básica ${ }^{3}$, como técnicos na sua área de formação, podendo se inserir no mundo do trabalho ou continuar seus estudos no nível superior.

No Paraná a ARCAFAR SUL ${ }^{4}$ tem uma forte relação com o governo do estado, principalmente com as Secretarias de Estado da Educação e da Agricultura, através de um convênio onde o Estado repassa recursos para a contratação dos monitores e faz a cedência de professores para o processo de escolarização. Também tem uma boa articulação com o governo federal, através da elaboração de projetos que recebem apoio, principalmente no que se refere a formação e a infraestrutura. A Associação de cada Casa tem parcerias principalmente com as prefeituras dos municípios de $\begin{array}{llll}\text { abrangência ostas localizadas } & \text { endão }\end{array}$

\footnotetext{
1 Professor de Sociologia da Rede Estadual de Educação do Paraná. Mestre em Educação pela Universidade Federal do Paraná - UFPR. Integrante do Grupo de Pesquisa de Trabalho e Educação da UEL e da Pesquisa: A prática pedagógica como mediação entre o conhecimento tácito e o conhecimento científico: metodologia para a Pedagogia do Trabalho

2 -A escolarização com a formação técnica começa nas Casas Familiares do Paraná em 2006 em apenas cinco (05) Casas.

${ }^{3}$ No Brasil temos dois níveis de ensino a Educação Básica e a Educação Superior, a Educação Básica é constituída de três etapas: A Infantil (4 a 5 anos), Ensino Fundamental (6 aos 14 anos) e Ensino Médio (15 aos 17 anos).

4 A Associação das Casas Familiares Rurais do sul do Brasil congrega os Estados do Paraná, Santa Catarina e Rio Grande do Sul, sua sede é no município de Barracão.
}

[Digite aqui] 


\section{SEMINÁRIO DE PESQUISA EM CIÊNCIAS HUMANAS - SEPECH \\ Humanidades, Estado e desafios didático-científicos \\ Londrina, 27 a 29 de julho de 2016}

\section{A PEDAGOGIA DA ALTERNÂNCIA NAS CASAS FAMILIARES RURAIS}

As CFRs surgem na França s como fruto de profundas reflexões dos agricultores familiares como reflexos das lutas sociais do homem do campo francês. O movimento que lançou as primeiras ideias sobre a superação dos problemas sociais através da organização social do homem francês no ano de 1899 surge como resultado da criação do movimento Sulco (Sillon) por jovens católicos comprometidos com as causas populares, porém é no $3^{\circ}$ Congresso do Sulco em Lyon, em 1904 que as Casas Familiares Rurais começaram a encontrar as condições concretas para a sua gestação, visto que foi neste encontro que foi organizado e criado o SULCO RURAL. Quatro anos depois no I Congresso Nacional Rural do Sillon, em laumes-Alésia é apontada de forma contundente a necessidade de se trabalhar a teoria e prática na formação do jovem rural influenciando a organização das Casas Familiares Rurais.

Em todos os documentos pesquisados que tratam do surgimento das CFRs na Franca reafirmam o surgimento das Casas como fruto da luta de movimentos populares em defesa dos ideais da democracia.

O que evidência no surgimento das CFRs é que os sujeitos ativos do processo tinham consciência de que estavam buscando alternativas concretas para a solução dos problemas da vida no campo francês.

No Brasil as CFRs nasceram sob influência da União Nacional das Casas Familiares Rurais (UNMFRs) francesas. Silva (2003) destaca três momentos por ocasião da implantação das CFRs no Brasil:

Um primeiro momento, no qual foram realizados os primeiros ensaios de organização das CFRs no nordeste brasileiro; um segundo momento, que registra a ocorrência da migração dos projetos das CFRs para o sul do Brasil, caracterizando, assim, a implantação e o desenvolvimento das primeiras experiências educativas no Paraná. Com a consolidação dessas experiências no Paraná, teve início um terceiro momento da trajetória das CFRs, com a sua expansão para outras regiões do Paraná, ao mesmo tempo em que ocorreu também o início dessas experiências em outros estados da Região Sul do Brasil. Poderíamos, ainda, inserir um quarto momento, referente à fase atual, em que vem ocorrendo uma expansão ofensiva das CFRs em vários estados brasileiros integrante da área de atuação da Superintendência de Desenvolvimento do Nordeste (SUDENE).

As primeiras CFRs no Estado do Paraná nascem em 1989, no município de Barracão e a partir da implantação no Paraná as CFRs expandiram-se para os Estados de Santa Catarina e Rio Grande do Sul e na seqüência para os Estados do Pará, Maranhão e Amazonas.

De acordo com Queiroz (2004) "Tanto as tentativas de implantação das CFRs no nordeste como no sul do Brasil, contaram com o apoio e recursos didáticos e financeiros de organismos federais e estaduais. No nordeste havia o apoio da SUDENE e no Paraná, houve desde o início, o apoio e a participação efetiva do governo estadual e das prefeituras. Juntou-se a isso o apoio da ONG belga DISOP/SIMFR e da embaixada francesa no Brasil".

O exemplo do modelo francês as Casas surgem no Brasil com forte ligação com o poder público e recebem apoio financeiro de entidades europeias, mas também dos governos estaduais e municipais. Para o seu funcionamento as Casas estão organizadas de forma tal que se torna essencial à proximidade com o poder local (prefeituras). 


\section{SEMINÁRIO DE PESQUISA EM CIÊNCIAS HUMANAS - SEPECH \\ Humanidades, Estado e desafios didático-científicos \\ Londrina, 27 a 29 de julho de 2016}

É importante citar que antes do surgimento das CFRs no Paraná a Pedagogia da alternância já estava sendo experimentada no Brasil desde 1969, embora bastante diferente com a implantação da Escola Famílias Agrícolas (EFAs) no estado do Espírito Santo, porém tanto no Paraná como no Espírito Santo os princípios que marcaram a efetivação da proposta foram à busca de alternativas para viabilidade e a potencialidade da agricultura familiar possibilitando aos agricultores e filhos de agricultores o acesso ao saber historicamente construído sistematizado a partir da sua própria realidade.

A história da Agricultura Familiar no Brasil é uma luta incessante, diária pela produção e reprodução das suas condições de vida, neste contexto as Casas Familiares Rurais e sua Pedagogia da Alternância apresentam-se como instrumento fundamental na perspectiva da autonomia do pequeno produtor familiar. As Casas Familiares Rurais estão fortemente relacionadas com o desenvolvimento rural em que os pequenos produtores são protagonistas do seu próprio desenvolvimento.

As Casas Familiares Rurais nascem e se desenvolvem no seio da Agricultura Familiar, estas por sua vez, trazem como característica a diversificação produtiva e a multifuncionalidade das atividades que são pensadas a partir das práticas sociais cotidianas dos agricultores e agricultoras familiares.

De acordo com Gimonet (1999), a Pedagogia da Alternância nasce para introduzir outro sistema educativo, originar um sistema no qual ela pode se constituir como um componente: Ela nos introduz num outro sistema educativo, pois a escola do século XX, tal qual a conhecemos e vivenciamos, será cada vez mais inadequada para este mundo veloz, em plena mutação no que diz respeito aos extraordinários avanços tecnológicos que caminham mais rápido do que o homem. Um mundo complexo que exigirá outra educação sistêmica.

A formação em alternância, a pedagogia da Alternância será um dos componentes da escola do futuro. (GIMONET, 1999, p. 39) O mesmo autor também nos alerta que a alternância pode se limitar a um simples método pedagógico, caso não seja constituída de todo o processo, não ficando, portanto restrita ao tempo e espaço. Ele denomina a Pedagogia da Alternância como "uma audácia pedagógica a um movimento educativo".

Apesar de muitos não gostarem de adotar esta definição, as CFRs são escolas da região, que devem ser "criadas e geradas por pessoas do lugar e para pessoas do lugar". Essa é uma importante e definidora característica de uma Casa. Ela deve nascer da vontade e da necessidade vivenciadas por um grupo de pessoas do lugar. Para criá-la, é necessário que as pessoas, os pais, os agricultores, a comunidade enfim, assumam o destino da educação de seus filhos.

Segundo Gimonet (1999), para a constituição de uma Casa são necessários os seguintes passos: - uma pequena estrutura escolar, próxima das pessoas, na qual cada um é valorizado e que baseia seu funcionamento na densidade e na qualidade das relações humanas; - a criação de uma associação de pais e outros do meio, como um espaço de intercâmbio, reflexão, exercício de responsabilidade, poder, formação e engajamento.

Como já se afirmou anteriormente, o projeto educativo das Casas Familiares Rurais nasce na França, tendo como inspiração os militantes do movimento socialdemocrata cristão. Esse movimento defendia o exercício da responsabilidade dos meios, o empenho do trabalho familiar e a assunção de seus próprios destinos. Mais tarde, foi influenciado pela corrente filosófica voltada para a pessoa. Essas influências 


\section{SEMINÁRIO DE PESQUISA EM CIÊNCIAS HUMANAS - SEPECH \\ Humanidades, Estado e desafios didático-científicos \\ Londrina, 27 a 29 de julho de 2016}

constituíram "um projeto personalista, humanista que coloca a pessoa em primeiro plano, mas não a pessoa sozinha, independente, e sim a pessoa com os outros, a pessoa fazendo parte da comunidade em função de um desenvolvimento em interação" (GIMONET, 1999, p.45).

De acordo com o autor, as Casas sempre tiveram uma dupla finalidade: a formação, a educação, a promoção, a inserção dos jovens no seu meio e a sua contribuição para o desenvolvimento e promoção do meio.

Outra característica é a compreensão de que se trata de uma pedagogia baseada na alternância. Isso significa que a alternância é de tempo, de local e de formação, com momentos socioprofissionais e em situação escolar - uma maneira de aprender, de se formar, associando teoria e prática, ação e reflexão, o empreender e o aprender dentro de um mesmo processo. Uma maneira de aprender pela vida, partindo de seu cotidiano, de momentos experienciais, colocando assim, a experiência antes do conceito, mas sem prescindir dele: A alternância em comparação com a escola tradicional inverte a ordem dos processos, colocando em primeiro lugar o sujeito que aprende suas experiências e seus conhecimentos e, em segundo lugar, o programa. O jovem ou o adulto em formação não é mais, neste caso, um aluno que recebe um saber exterior, mas um ator socioprofissional que busca e que constrói seu próprio saber. Ele é sujeito de sua formação, ele é produtor de seu próprio saber. (GIMONET, 1999, pág. 45).

Também é uma característica a diversidade dos formadores, constituídos dos monitores que trabalham nas Casas, de pais e de outras pessoas do meio socioprofissional, pois o tempo família e o tempo comunidade são partes do processo formativo. A ideia é que cada um possa contribuir com o seu saber específico ao tema de estudo, para que o jovem possa receber e perceber diferentes pontos de vista, ou de conhecimentos complementares. Assim, a pedagogia da Alternância compreende que é preciso partilhar o processo educativo. Nas palavras de Gimonet (1999, pág. 45), “[...] a pedagogia da Alternância conduz à partilha do poder educativo. Ela reconhece e valoriza o saber de cada um e dos contextos de vida. A pedagogia da Alternância é uma pedagogia da parceria".

Ainda com relação aos formadores, nas Casas eles são denominados monitores e não professores. A justificativa para isso é a contraposição ao sistema tradicional, que trata o conhecimento de maneira fragmentada, em disciplinas. O trabalho deve ser desenvolvido por uma equipe educativa. Outra característica diz respeito à estrutura educativa, constituída pelo acolhimento e pela consideração positiva de cada jovem e de suas famílias. Também é uma condição à vida em pequenos grupos, o que é realizado pelo internato, onde o convívio social é um exercício diário, por meio das funções e tarefas de uma Casa, e aos tempos de trabalho e vida compartilhados.

O trabalho metodológico das CFRs é todo organizado no chamado plano de formação, constituído por uma série de instrumentos com o objetivo de uma formação integral para os jovens. O jovem articula os saberes pessoais, de sua família e do seu meio socioprofissional com os saberes tecnocientíficos. Com isso, pretende-se que compreenda melhor a situação do seu cotidiano e as suas possibilidades de superação. 


\section{SEMINÁRIO DE PESQUISA EM CIÊNCIAS HUMANAS - SEPECH \\ Humanidades, Estado e desafios didático-científicos \\ Londrina, 27 a 29 de julho de 2016}

\section{A CARACTERIZAÇÃO DAS CASAS PESQUISADAS}

Foram definidas três Casas Familiares Rurais no Estado para a realização desta pesquisa, uma na região central no município de Santa Maria Do Oeste ${ }^{5 \%}$, com o curso de Técnico em Agropecuária, a segunda na região norte do estado, no município de Sapopema $^{6}$, , com o curso de Técnico em Agropecuária e a terceira na região sul, no município de Pinhão ${ }^{7}$, com o curso de Agroecologia. Todas as Casas possuem uma boa estrutura com alojamentos para os jovens.

O município de Santa Maria Do Oeste tem a população de 11.500 habitantes, sendo que a maioria da população, 8289 habitantes residem no campo. A abrangência de atendimento da Casa é de 08 municípios da região, todos com baixa densidade populacional. A característica da região é de pequenos agricultores que estão na região há várias gerações. As atividades desenvolvidas são referentes ao leite, é uma região de bacia leiteira, da criação de bovinos, galináceos e suínos e da agricultura de subsistência.

O município de Sapopema tem a população de 6.736 habitantes, destes 3.184 residem no campo, portanto entorno de 50\%. A Casa Familiar tem abrangência 05 municípios. Uma das características é uma grande concentração de assentamentos rurais da reforma agrária, originários do Movimento Sem Terra - MST. A organização da Casa é bastante sintonizada com o Movimento dos Trabalhadores Sem Terra, de onde vem boa parte dos jovens. A região é, portanto de pequenos agricultores com atividades bastante diversificadas entre elas o café, cana de açúcar, milho, soja, gado de corte, leiteiro, galináceos e suínos.

O município de Pinhão tem 30.208 habitantes, sendo que desses, 14.317 estão no campo, quase $50 \%$ da população. A Casa atende a 08 municípios da região que também são de baixa densidade populacional. Os jovens são oriundos de pequenas propriedades rurais, as principais atividades da região são a agricultura, horticultura, fruticultura, aveia, batata inglesa, cevada, feijão, a erva - mate e agricultura de subsistência, também é produtora de gado de corte e leite, galináceos, ovinos e suínos.

$\mathrm{Na}$ Casa Familiar de Santa Maria do Oeste foram entrevistados dez (10) jovens, dos quais sete (07) mulheres e três (03) homens, sendo sete (07) egressos e três (03) cursando. A idade dos egressos é de 18 a 22 anos e dos jovens que ainda estão cursando de 15 a 19 anos. As entrevistas ocorreram nas propriedades rurais e nos locais de trabalho, empresas agropecuárias. Todos moram nas propriedades rurais, isso é reforçado na seleção, pois é um dos critérios de seleção que os jovens sejam filhos de agricultores.

Foram entrevistados na Casa Familiar Rural de Sapopema 12 jovens, sendo dois (02) homens e uma (01) mulher que ainda cursam, na faixa etária de quinze (15) a dezenove (19) anos e quatro (04) mulheres e cinco (05) homens egressos na faixa etária de dezoito (18) a vinte e sete (27) anos. As entrevistas dos jovens ocorreram nas

\footnotetext{
5 A Casa Familiar Rural de Santa Maria do Oeste esta localizada na Comunidade Chapéu do Céu, s/n, CEP 85230-000, no município de Santa Maria do Oeste, telefone: (42)36441003 ramal 23.

${ }^{6}$ A Casa Familiar Rural "Padre Sasaki” de Sapopema esta localizada na Estrada Salto das Orquídeas, Km 03, CEP 84290-000, no município de Sapopema, telefone (43)35481061.

${ }^{7}$ A Casa Familiar Rural de Pinhão esta localizada na Rua Nilo Vivier, 73 Mazurechi, CEP 85170-000, município de Pinhão.
} 


\section{SEMINÁRIO DE PESQUISA EM CIÊNCIAS HUMANAS - SEPECH \\ Humanidades, Estado e desafios didático-científicos \\ Londrina, 27 a 29 de julho de 2016}

propriedades dos jovens e suas famílias e em alguns casos no local de trabalho dos mesmos. Pudemos constatar nas entrevistas que todos são filhos de agricultores familiares rurais, isto é uma consequência da forma de seleção da Casa que tem como critério que os jovens sejam filhos de agricultores. Os jovens moram nas propriedades sendo que a maioria atua diretamente nas propriedades das famílias, mesmo os que trabalham como técnicos em cooperativas ou empresas agropecuárias, apenas uma jovem egressa do curso técnico não trabalha diretamente na agricultura.

Na Casa Familiar Rural de Pinhão foram entrevistados onze (11) jovens, sendo três (03) mulheres e oito (08) homens, sete (07) egressos e quatro (04) cursando. Os egressos têm a idade entre dezoito (18) a vinte e dois (22) anos e os jovens que ainda cursam tem a idade entre quinze (15) a dezessete (17) anos. As entrevistas ocorreram na Casa Familiar com os jovens que ainda estão em formação e, as com os egressos, nas propriedades onde moram e trabalham.

Também foram entrevistados outros agentes como coordenadores e monitores das Casas, pais dos jovens, os três (03) presidentes das Associações de cada Casa Familiar pesquisada, os coordenadores pedagógicos regionais da ARCAFAR/SUL das regiões onde as três Casas estão localizadas.

\section{DE ALUNOS A EGRESSOS A TRAJETÓRIA EM UMA CASA FAMILIAR RURAL}

A grande maioria dos jovens estudou no Ensino Fundamental na Casa Familiar Rural ou em escolas públicas da região. Conheceram as Casas através de amigos ou de parentes que estudaram nas mesmas. Todos participam da alternância, isto é, ficam internos durante uma semana na Casa e na outra semana em alternância na propriedade familiar.

Em todas as Casas existe um processo de seleção que consiste em entrevistas com os jovens e suas famílias, sendo um dos principais critérios que sejam filhos de agricultores. É preciso ressaltar, no entanto, que existem casos em que os jovens moram em municípios essencialmente agrícolas, onde a população vive da agricultura, mas que não residem na mesma, mas tem algum vínculo familiar ou afinidade com o trabalho no campo.

As primeiras constatações são que a maioria dos jovens são filhos de pequenos agricultores familiares, que buscam a sua subsistência através da terra, portanto a oferta de cursos voltados para a agricultura condiz com a expectativa de vida e trabalho no presente e futuro. No presente porque estes jovens estão conseguindo ainda durante o curso através de a alternância produzir mudanças na forma de gestão e produção nas propriedades da família, sem causarem conflitos com os conhecimentos que os pais adquiriram na vida e no trabalho diário. No futuro porque está abrindo possibilidades antes não pertencentes no imaginário do agricultor familiar rural, pois além de seus filhos conseguirem uma formação que os mesmos não tiveram a possibilidade de ter, haja vista que dos 99\% dos pais entrevistados não tinham mais que quatro (04) anos de estudo formal, e hoje muitos de seus filhos estão dando continuidade a sua formação em nível superior.

Dos jovens entrevistados apenas uma egressa não trabalha diretamente no campo, trabalha como ajudante de cozinha em um restaurante local, mas tem uma 


\section{SEMINÁRIO DE PESQUISA EM CIÊNCIAS HUMANAS - SEPECH \\ Humanidades, Estado e desafios didático-científicos \\ Londrina, 27 a 29 de julho de 2016}

relação familiar diária com o campo, até porque o município onde reside é eminentemente rural. $\mathrm{Na}$ grande maioria os jovens permanecem na propriedade da família contribuindo com o trabalho coletivo e melhorando as condições de produção familiar, mas também criam seus espaços para projetos individuais. É preciso destacar que os jovens passam a exercer na comunidade no território um papel importante pois agregam novas tecnologias na produção.

Também foram constatadas nas entrevistas e nas visitas as propriedades que os jovens possuem conhecimento técnico/científico do trabalho que estão desenvolvendo, fato inclusive relatado por alguns pais entrevistados de que muitas dúvidas ou formas de trabalho que foram adotadas ultimamente nas propriedades foram trazidas pelos jovens orientados pela formação desenvolvida na Casa Familiar e muitas vezes ampliada com as visitas técnicas dos monitores no momento de alternância.

Outra característica observada foi do sentido do cooperativismo, parece ser condição básica e fundamental para a subsistência da agricultura familiar, muito difundida na formação destes jovens. Isto aparece na fala dos jovens e famílias como uma necessidade concreta para o fortalecimento e sobrevivência dos mesmos.

Todos os jovens já concluintes/egressos atribuem um peso grande no seu sucesso profissional aos conhecimentos adquiridos na Casa Familiar Rural, alguns atribuem a alternância à possibilidade de terem estudado, porque não poderiam deixar de participar da vida produtiva da família de forma diária, outro fator é o da falta de oferta de escolas na etapa de nível médio e técnico no meio rural em nosso país, um problema ainda não resolvido no Brasil.

Os jovens quando indagados sobre o seu lazer apontam como as principais atividades, o futebol que é um esporte bastante difundido em nosso país, os programas de televisão aberta, a utilização da rede de internet como meio de comunicação, passeios com os amigos e de uma atividade tipicamente rural, o rodeio seja para assistir ou competir. É importante destacar que quando eles citam o rodeio, os mesmos salientam tratar-se do rodeio de "laço estendido", esta modalidade de rodeio segundo a fala de alguns tem um diferencial aos demais, pois ele não agride ou fere o animal. Isto pode nos indicar uma preocupação gerada pela conscientização da proteção e cuidado dos animais, como forma de garantir sustentabilidade sócio-ambiental do meio onde vivem, conceito este muito trabalhado no processo formativo destes jovens.

Isto é constatado na fala de um pai, que também é presidente de uma das Casas, quando afirma que após o filho entrar na Casa passou a cuidar melhor dos animais, inclusive parou de caçar e passou a vigiar e proibir a caça ao redor da propriedade. Fala que encontra ressonância com o relato dos monitores e coordenadores em relação a proteção e sustentabilidade ambiental.

Outro destaque é que boa parte dos jovens egressos e também os que ainda estão em formação na Casa mudaram seu projeto de vida inicial, mas relatam que as mudanças foram sendo construídas no decorrer do processo formativo e que as mesmas foram mudanças para melhor. Um elemento que foi percebido nas entrevistas com os jovens é que eles passam a adotar uma prática e disciplina de pesquisa, sempre procurando novas informações e inovações para ser implantado buscando a melhoria da produção e comercialização da produção. Os jovens em formação assim como os egressos destacam que a alternância possibilita a criação de um grande vínculo com os coordenadores, monitores e professores recorrendo a estes, mesmo depois de terminarem o curso, quando tem dúvidas ou necessidade de troca informações. Os 


\section{SEMINÁRIO DE PESQUISA EM CIÊNCIAS HUMANAS - SEPECH \\ Humanidades, Estado e desafios didático-científicos \\ Londrina, 27 a 29 de julho de 2016}

jovens que informaram que não mantém contato com os profissionais das Casas alegaram que o principal motivo é a distância entre a propriedade onde vivem e as Casas. Com relação o vínculo é percebido por todos, família e jovens que a alternância possibilita que as relações entre eles não se quebrem, ao contrário sejam fortalecidas, pois não se afastam da família por um grande período de tempo, isto também contribui para que as inovações tecnológicas trazidas pelos jovens não criem um afastamento ou uma rejeição por parte da família. Segundo os familiares a alternância trouxe aos jovens um maior vínculo com a família e com a propriedade, foi relatado por alguns pais que antes de iniciar o processo formativo nas Casas os jovens demonstravam pouco ou nenhum interesse pela vida no campo, em alguns casos verbalizavam o sentimento de inferioridade por viver e trabalhar no campo. Isto foi revertido logo nos primeiros meses quando passaram a compreender a construção histórico-social da identidade camponesa, tema este problematizado nas Casas Familiares Rurais pelos professores e monitores.

É unânime entre os jovens entrevistados que foi positiva sua passagem pelas Casas, que muito contribuiu para o seu desenvolvimento intelectual e pessoal. Fato este confirmado por vários professores e monitores quando relatam o desenvolvimento $\mathrm{e}$ desenvoltura na defesa de suas ideias nos planos de estudo e nas colocações em comum.

As Casas possuem professores que são os responsáveis pela formação básica, isto é, professores das disciplinas que compõem as áreas de conhecimento obrigatórias pela legislação educacional brasileira, quais sejam, Área de Linguagens, Ciências da Natureza, Ciências Humanas e Matemática e de monitores que são os responsáveis pela área técnica específica de cada curso técnico.

Tanto os professores e monitores relatam a satisfação em trabalhar com a Pedagogia da Alternância e entendem que ela muito contribui para a inclusão escolar do segmento da agricultura familiar no ensino formal, mas com o diferencial de uma proposta voltada para a realidade concreta da população do campo. Entendem também que a Pedagogia da Alternância pode se constituir como uma política pública para a educação do campo, mas que a educação por si mesma não dá conta de atender sozinha os diversos direitos da população do campo, sendo necessário a constituição de políticas públicas intersetoriais que possibilitam o direito e as condições de permanência do agricultor familiar no campo.

A maioria dos professores e monitores entrevistados que atuam nas Casas tem vínculos familiares com o campo, isto possibilita uma maior interação com os jovens e a comunidade, um fator destacado como importante pelos coordenadores e pela Associação, pois há uma compreensão das necessidades reais da região de abrangência das Casas Familiares Rurais. Um fator preponderante destacado é o planejamento ser elaborado de forma coletiva pelos coordenadores com os professores e monitores possibilitando a integração e a interdisciplinaridade, soma-se a isto o acompanhamento personalizado dos jovens, inclusive com o contato com a família em desenvolvimento das alternâncias nas propriedades o que contribui para a participação efetiva das famílias em todo processo de aprendizagem dos alunos.

\section{ALGUMAS CONCLUSÕES}

Como conclusões preliminares pode-se constatar que as Casas Familiares Rurais têm alcançado seu objetivo proposto, ou seja, promover a formação técnica profissional 


\section{SEMINÁRIO DE PESQUISA EM CIÊNCIAS HUMANAS - SEPECH \\ Humanidades, Estado e desafios didático-científicos \\ Londrina, 27 a 29 de julho de 2016}

de jovens filhos de agricultores rurais sendo fiéis aos seus princípios fundantes, valorização da identidade cultural camponesa.

Em contato com os jovens, tanto os egressos como os cursando, pode-se perceber a disciplina de pesquisa adquirida por estes, a todo momento, fazem questão de explicar qual a metodologia de trabalho que estão desenvolvendo, indicando as fontes pesquisadas e os últimos avanços, novidades, no que se refere a tecnologia de produção agrícola e/ou agropecuária. Dando continuidade à prática adquirida na Casa Familiar mantém contato permanente com outros produtores trocando experiências e informações inclusive visitando feiras agrícolas e campo experimentais de produção agrícola a fim de subsidiar sua atividade profissional.

É identificado nesta pesquisa, conforme relato dos jovens que estudam nas Casas, algumas explicações em relação ao êxito do trabalho pedagógico diferenciado, uma primeira é que os mesmos não teriam outra oportunidade de estudo se não fosse em Alternância, portanto essa é reconhecida como um diferencial que possibilita o não afastamento do jovem da família e da sua participação nas tarefas cotidianas nas propriedades. Percebe-se que a grande maioria desses jovens está inclusa no sistema regular de ensino graças a essa forma de organização escolar, sem a qual é quase certo que estariam fora da escola reproduzindo o histórico escolar de seus progenitores. Outra explicação é de que muitos não conseguiam aprender na escola regular e na Casa pelo trabalho ser personalizado percebem que a aprendizagem ocorre, portanto acreditam que o curso é o que melhor atende suas necessidades de vida e profissional.

A pesquisa possibilitou chegarmos à conclusão que os jovens a partir da formação nas Casas têm alcançado maior autonomia sócio profissional tendo conseguido melhores oportunidades de ganhos reais a partir do desenvolvimento de atividades profissionais para a qual se prepararam no processo formativo desenvolvido em alternância.

Constata-se que se a Pedagogia da Alternância possibilita o acesso desses jovens a um curso técnico profissional de qualidade sem com isto terem que abandonar a propriedade da família. Uma vez formado estes jovens estão aptos a exercerem a prática profissional que escolheram. Neste sentido as Casas através da Pedagogia da Alternância realmente têm contribuído para a inserção sócio profissional desses jovens, filhos de agricultores familiares rurais.

\section{REFERÊNCIAS}

GIMONET,J.C. Nascimento e desenvolvimento de um movimento educativo: as Casas Familiares Rurais de educação e orientação. In: Seminário Internacional da Pedagogia da Alternância: alternância e desenvolvimento. Anais UNEFAB, Salvador, 1999.

QUEIROZ, J.B.P. Construção das Escolas Famílias Agrícolas no Brasil. Ensino Médio e Profissional. Tese de Doutorado. Universidade Nacional de Brasília UNB, 2004.

SILVA, Lourdes Helena da. As experiências de formação de jovens do campo: alternância ou alternâncias? Viçosa, MG: UFV, 2003. 